\title{
Acceptance and Commitment Therapy for Pediatric Chronic Pain: Theory and Application
}

\author{
Melissa Pielech ${ }^{1, *}$, Kevin E. Vowles ${ }^{1, *}$ and Rikard Wicksell ${ }^{2}$ \\ Department of Psychology, University of New Mexico, Albuquerque, NM 87131, USA \\ 2 Department of Clinical Neuroscience, Karolinska Institutet, SE-171 76 Stockholm, Sweden; \\ rikard.wicksell@karolinska.se \\ * Correspondence: melissapielech@gmail.com (M.P.); k.e.vowles@gmail.com (K.E.V.); \\ Tel.: +1-505-277-1394 (K.E.V.)
}

Academic Editor: Lynn S. Walker

Received: 4 October 2016; Accepted: 25 January 2017; Published: 30 January 2017

\begin{abstract}
Acceptance and Commitment Therapy (ACT) is a third wave behavior therapy approach which aims to increase engagement in activities that bring meaning, vitality, and value to the lives of individuals experiencing persistent pain, discomfort, or distress. This goal is particularly relevant when these aversive experiences cannot be effectively avoided or when avoidance efforts risk their exacerbation, all of which may be common experiences in children and adolescents with chronic pain conditions. The primary aim of the present paper is to review and summarize the extant literature on the application, utility, and evidence for using ACT with pediatric chronic pain populations by: (1) defining the theoretical assumptions of the ACT model; (2) summarizing research study findings and relevant measures from the published literature; and (3) critically discussing the strengths, limitations and areas in need of further development.
\end{abstract}

Keywords: Acceptance and Commitment Therapy; ACT; children; adolescents; pediatric; chronic pain; pain acceptance

\section{Introduction}

A significant percentage of young people experience chronic pain, generally defined as pain that persists for three months or longer [1]. A subset of these patients report marked deficits in healthy functioning [2] and commonly experience comorbid mental health difficulties that can persist into adulthood [3]. Treatment efforts for chronic pain often highlight the primacy of pain reduction or elimination. Such efforts to minimize current pain and avoid it in the future are perfectly natural. In acute cases, efficient pain escape and avoidance behaviors can have genuine adaptive value, as they minimize risk of morbidity and mortality by allowing for efficient detection and response to painful or potentially painful situations [4-6].

In the case of chronic pain, however, these perfectly natural responses may not be the most adaptive. In fact, when persistent, avoidance behaviors can be reliably associated with significant disruptions in physical, social, and emotional functioning across the lifespan, often without any corresponding decrease in pain. A prime and well-established example of these findings is the fear-avoidance model, which consistently indicates that more persistent and widespread efforts to avoid pain are associated with worse current and future functioning in both pediatric and adult settings [7-11]. In youth, the role of caregiver responses to pain is also highly relevant, as high fear-avoidance in parents or responses to the child's pain that reinforce avoidance are related to greater levels of child distress and disability [12-14]. Thus, when pain avoidance is a primary goal in youth and their caregivers, there appears to be a heightened risk that pain will be more disruptive in important areas of physical and psychosocial functioning [15,16]. 
Youth with chronic pain and their family systems are therefore likely in need of treatments that emphasize effective responding to pain, with less reliance on pain control. It is possible that effective responding to chronic pain requires somewhat paradoxical responses to pain. Such paradoxical responses might include, for instance, decreasing pain avoidance attempts, particularly when they are ineffective at avoiding pain over the longer term or when they negatively impact important functioning. Further, effective responding to pain may actually include "approach" behaviors, such as participation in meaningful activities even when pain is present. Importantly, adoption of such strategies requires careful consideration regarding whether one is willing to experience pain in the service of engagement in meaningful activities. Acceptance and Commitment Therapy [17] aims to improve the ability to act in alignment with personal values while in the presence of potentially interfering pain and distress, a response pattern defined as psychological (or behavioral) flexibility. As part of this process, the individual is encouraged to explore and challenge the utility of avoidance, as well as acceptance-oriented strategies, in managing chronic pain. The primary aim of the present paper is to provide a narrative review and summary of the extant literature on the application and utility of ACT specifically for pediatric chronic pain. First, we review the primary goals and theoretical assumptions of the ACT model. Second, we summarize treatment outcomes and relevant measures from the published literature. Finally, we discuss strengths, limitations, and areas in need of development.

\subsection{The ACT Model}

While a full review of the theoretical and philosophical assumptions of the ACT model is beyond the scope of the present review (see Hayes et al. [17] for more information), it is important to highlight a few key points. The first is to emphasize the overarching goal of ACT, which is to increase successful engagement in activities that bring meaning, vitality, and importance to the lives of individuals experiencing persistent pain, discomfort, or distress. This goal is particularly relevant when these aversive experiences cannot be effectively avoided or when avoidance efforts risk their exacerbation, as is often the case with persistent pain. Each of the following conceptual assertions circle back to this overarching goal.

ACT is based on the philosophical positions of both pragmatism and functional contextualism [18]. Its pragmatic goal is "effective action," meaning it aims to facilitate the effectiveness of behavior in achieving adaptive and functional goals over the longer term. At the level of actual clinical interaction, this goal is described in terms of greater engagement in valued actions. The functional contextual orientation of ACT allows one to define two primary aims: (1) accurate prediction and (2) useful influence on behavior [19]. The pursuit of these aims requires one to attend to the relevant contextual events in any analysis of behavior, including historical events giving rise to the behavior as well as relevant ongoing events in the person's environment. Practically, ACT seeks to undermine the influence of key current and historical stimuli that contribute to ineffective responses to pain, such as persistent avoidance, and bolster the influence of those that contribute to more effective responses, such as the specification and pursuit of desired valued outcomes. These aims of "accurate prediction" and "useful influence on behavior" are concordant with the operant behavioral roots of both ACT and Cognitive-Behavioral Therapy (CBT; [18,19]).

Much discussion has occurred regarding the similarities and differences amongst ACT and other forms of psychotherapy, principally Cognitive Behavioral Therapy (CBT; for information regarding applications of CBT for pediatric chronic pain, please refer to $[20,21])$. We suggest that there are two key differences between these approaches. The first is the central focus on the facilitation of values-based actions in ACT. While such a focus is both fully compatible and at times apparent within CBT (e.g., [18,19]), its centrality in ACT is distinctive. The second key difference pertains to working with human language and cognition. In brief, ACT seeks not to directly alter the occurrence of certain instances of human cognition (e.g., catastrophic thinking) and sensation (e.g., pain intensity), but to 
increase the repertoire of responses to these cognitions and sensations, as well as the flexible use of them, to facilitate actions more in line with valued activities over the longer term.

The experimental pain literature provides several examples regarding the utility of altered responding to human cognition and sensation in adults. One of the earliest experimental trials of acceptance involved an acute pain induction task, where participants were asked to submerge a hand into an ice water bath and were randomized to a pain control (e.g., keep your pain under control; don't let it increase) or pain acceptance (e.g., let your pain be; don't let it control your responses) set of instructions [22]. Results indicated that tolerance time for participants in the latter condition were significantly longer than the former. Importantly, participants in the pain acceptance condition viewed pain and thoughts about pain as less influential than those in the pain control condition. This pattern of results has been replicated several times in studies with experimentally induced pain and healthy controls [23-27], as well as in adults with low back pain [28]. Furthermore, laboratory studies suggest that the inclusion of values in experimental pain settings is important. For example, when a pain task is paired with a personally important reason for experiencing the pain, tolerance times tend to be increase and the experience of pain is viewed as a less important determinant of behavior $[27,29]$.

The clinical model of ACT specifies several related treatment processes, each of which is intended to help facilitate more effective responding to difficult or aversive experiences. For example, the central overarching process has been termed "psychological flexibility," which can be simply defined as effectively and flexibly responding to aversives such that engagement in important areas of living is maintained at a level that is sufficient for the needs of the individual $[17,30]$. Thus, an instance of psychological flexibility in an adolescent with chronic pain may be maintenance of social and scholastic engagement even with the ongoing experience of chronic pain and including times when pain is low as well as when it is high (see Wicksell et al. [31], summarized below, for description of a case example).

Underlying this overarching process of psychological flexibility are three pairs of "sub" processes [17]. These three pairs include (1) acceptance and defusion; (2) moment-to-moment awareness and a transcendent sense of self; and (3) clarity and committed action in pursuit of valued activities (e.g., see [17] for details, as well as [32] for an empirical evaluation of this model in chronic pain). Acceptance and defusion refer to patterns of responding to pain that involve acknowledgement that pain and suffering are a normal part of life many times and choosing to work with these experiences rather than try to avoid or control them [33-35]. Moment-to-moment awareness and a transcendent sense of self refer to aspects of mindfulness that seek to increase consistent, nonjudgmental attention to the present moment, less struggling with present experiences, and the facilitation of a stable sense of self as a person having experiences, rather then an unstable sense of self as a person who is defined by the experiences themselves (see [36,37]). Finally, clarity and committed action in relation to values includes a definition of useful, valued directions to help guide behavior while in the midst of difficult circumstances, as well as a flexible commitment to these values such that behavior can be adjusted over time to facilitate consistent movement towards them [38].

Thus, treatment success in ACT for pediatric chronic pain could be defined as the occurrence of effective responding to the natural variations in pain intensity that occur, such that personal needs and goals are being met or progressed. Furthermore, the model assumes that such treatment success is most likely to occur when one is (1) aware of pain when it is occurring, but is not consumed by that experience to the exclusion of other things happening; (2) aware of present experiences as they are occurring and able to let these experiences come and go; and (3) clear on valued areas and engaged in a flexibly persistent pattern of behaviors to pursue these areas. Overall, the relevance of these processes in adult chronic pain is reasonably well-established in that measures of these processes are reliably and significantly related with pain-related distress, disability, and healthcare use [39-41].

In the case of pediatric pain treatment specifically, this model applies to both caregiver and child. Much like caregiver responses are important in the fear-avoidance model, greater caregiver acceptance of pain and discomfort is associated with less restricted functioning in children [42,43]. Thus, it can be hypothesized that parental support of the child's engagement in valued activities in the presence of 
pain via operant approaches may be helpful to the child's overall success in adapting effectively to a chronic condition.

\subsection{Developmental Considerations}

ACT has been successfully adapted and implemented for use with a wide range of pediatric populations including youth with chronic pain (e.g., [44]), cystic fibrosis [45], and anxiety disorders [46], as well as medical conditions that involve pain as a primary symptom [47]. For a review of the application of ACT more broadly with pediatric populations with physical health conditions, please refer to [48]. Given the inherent level of abstraction in some ACT concepts, developmentally sensitive modifications in the language and delivery of treatment may be necessary. Adaptations should be made based on clinical judgment and awareness of the patient's level of cognitive, social, and psychological functioning, as well as abstraction abilities (refer to [49] for a discussion of adapting ACT interventions for adolescent populations). Briefly, adaptations may include age-appropriate simplification of language of complex concepts, such as referring to distressing, pain-related thoughts as coming from a "pain monster" whose advice may serve to restrict functioning and effective engagement in valued activities [31]. Concrete strategies can be used for teaching abstract concepts, like facilitation of values identification by using a heart shaped box that is filled with slips of paper describing patient values or teaching mindfulness via a walking exercise [50]. There are also numerous ACT metaphors that are developmentally relevant for use with adolescents, though it is recommended that use of metaphors be chosen with consideration to the patient's social context and interests. It can also be helpful to reiterate and repeat important topics to reinforce understanding. Additionally, the importance of family factors and inclusion of parents/caregivers in pediatric pain treatment is of clear importance [14,31,51]. From an ACT perspective, more traditional behavioral strategies such as contingency management may favorably be combined with interventions aimed at improving the parent's ability to self-manage distress, which otherwise may interfere with effective coaching [33].

\section{The Evidence-Base for ACT with Youth with Chronic Pain}

\subsection{Search Criteria}

Relevant treatment outcome papers using ACT published through December 2016 were identified through searches on PubMed and PsychInfo using search terms such as 'Acceptance and Commitment Therapy' or 'ACT' and 'children,' 'adolescents,' 'youth,' or 'pediatric' and 'chronic pain.' The evidence base for using ACT with youth for chronic pain is modest, and includes one case study, one case series, two randomized controlled trials, and three prospective cohort studies. Each of these studies is reviewed below. In addition, a fourth cohort study is also reviewed. While the study described a CBT-based intervention, mediation analyses were done using a measure of pain acceptance, thus the outcomes seem relevant to include.

\subsection{Case Study and Case Series}

The first study in the field of ACT for pediatric chronic pain is a case study by Wicksell et al. [33] that facilitated development of ACT treatments for youth with chronic pain and was helpful in distinguishing between ACT and CBT in the context of chronic pain rehabilitation. The patient was a 14-year-old female, who had been experiencing persistent pain for three years. Her array of symptoms were conceptualized as "musculoskeletal pain syndrome" and included generalized joint and body pain, persistent headaches, and features of panic attacks with subsequent school absence, social isolation from friends, and withdrawal from valued activities. Treatment was rehabilitative in nature and primarily consisted of exposure to stimuli related to pain and distress, including avoided activities and places, as well as significant values clarification exercises. Treatment comprised a total of 13 sessions over a six-month period, with three of the 13 sessions including both patient and parents. At discharge, improvements were noted in functional disability, engagement with valued activities, 
scholastic involvement, and avoidance of emotions. Importantly, these improvements were sustained during a six-month follow up period.

In 2007, a follow-up case series was published describing findings from an individual ACT-based treatment approach used with 14 adolescents (11 females, mean age $=17$ years, standard deviation $(\mathrm{SD}=2.1)$ with chronic pain and high levels of pain-related disability [52]. Primary outcome variables were disability and school attendance. Treatment emphasized exposure to private events and previously avoided activities, values clarification and use of values as guiding principles for engagement in exposure, as well as acceptance of distressing and negative feelings. Treatment length varied from 5-29 weekly sessions and included individual sessions with parents, as needed. Significant improvements were observed in the primary outcomes variables, which were maintained through 3 and 6-month follow-ups. Significant improvements were also observed in levels of pain catastrophizing, pain intensity, and pain interference.

\subsection{Randomized Controlled Trials (RCT)}

Following the case study and pilot case series, Wicksell et al. [44] published the first RCT evaluating the effectiveness of an ACT-based treatment for children and adolescents with chronic pain. ACT was compared to a multidisciplinary treatment (MDT) including amitriptyline medication. The primary components of the 10-week ACT-oriented treatment group were acceptance strategies and exposure, with sessions occurring weekly. A total of 32 youth participated (mean age $=14.8$ years, $\mathrm{SD}=2.4$ ) with 16 patients randomized to each condition. Patients in the ACT condition improved significantly in multiple domains (e.g., functional disability, health related quality of life) and changes were sustained through follow up, as evidenced by multiple large effect sizes. Patients in the MDT group improved in many domains, as well, but across conditions, patients who received ACT improved significantly more in levels of pain-related fear, overall quality of life, pain intensity, and pain interference. A prolonged treatment period in the MDT condition complicated comparisons at follow up, but results demonstrated the relative utility of ACT in comparison to a multidisciplinary treatment.

In a planned set of post-hoc analyses, Wicksell et al. used data from this same RCT to identify mediators of treatment outcome [41]. Tested mediators were pain intensity, as well as both CBT- and ACT-consistent variables, including self-efficacy, catastrophizing, kinesiophobia, pain-impairment beliefs, and pain reactivity. Only these last two variables, which were argued to be representative of a more flexible and willing pain response style, were shown to be significant mediators of change. Furthermore, in subsequent analyses these same two mediators were independent predictors of outcomes at follow-up for the ACT condition only. Although tentative, the pattern of results suggests that variables consistent with psychological flexibility mediate the effects of ACT-based interventions to improve functioning in patients with chronic debilitating pain.

In a more recent study, Ghomian and Shairi [53] compared an ACT based treatment $(n=10)$ with a control condition $(n=10)$ in children ages 7 to 12 with chronic pain. Details regarding treatment components or the control condition were not provided (Note. the study authors were emailed a request asking for further details regarding treatment and control conditions and no response was received). Data was collected at four time points: pre-treatment, discharge, and 3.5 and 6.5 months post-treatment. Regarding results, patients in the ACT condition reportedly demonstrated significantly greater improvements in functional disability at the end of treatment and through the follow up time points.

\subsection{Prospective Cohort Studies}

Gauntlett-Gilbert et al. [54] evaluated outcomes from a 3-week residential, interdisciplinary ACT-based program ( $\sim 90 \mathrm{~h}$ of treatment) for adolescents $(n=98)$ with chronic pain. The program, comprised of physical conditioning, activity management, and psychology, also included parent involvement in most sessions, with the exception of a four-day period where parents received therapy separately from their child. Data on self-reported functioning (e.g., depressive and anxious symptoms, 
levels of pain acceptance) and objective physical ability was collected from child and parent across three time points: baseline, three weeks after discharge from treatment, and at a three-month follow up time point. Patients improved across all domains of functioning in a manner that was theoretically consistent with ACT whereby improvements occurred without efforts to control pain or manipulate cognitions. Additionally, improvements in pain-related acceptance were associated with better treatment outcomes, suggesting a key role of acceptance in pediatric pain rehabilitation.

Martin et al. [55] published outcomes of a feasibility trail of ACT for adolescents with chronic pain and Neurofibromatosis type 1 (NF1), an autosomal disorder. The sample included 10 adolescents, who averaged 17 years of age and seven parents, who participated in a two day group intervention provided in a "workshop" format. At a three-month follow-up, significant declines in pain interference were reported by both patients and parents, while patients only reported decreased pain intensity. The authors suggested that the obtained data supported the feasibility of ACT in young people diagnosed with NF1.

\section{Prospective Studies with Parents}

Recently, Wallace et al. [56] published the first pilot study examining the application of an eight-week, ACT-based group intervention with parents ( $n=8 ; 6$ completed the study) of youth with chronic pain. The primary treatment target was to increase parental psychological flexibility, specifically for parents to identify areas of ineffective action or stuckness within themselves and their family unit, as well as develop strategies to support pursuit of values-based action. Sessions were delivered once a week, on an outpatient basis, and were $75 \mathrm{~min}$ long (session by session content is detailed by the authors in the manuscript [56]). Measures of parent psychological flexibility, responses to child pain symptoms, and levels of pain interference were collected during treatment and at three follow up time points, up to six months post treatment. Overall, parents were highly satisfied with the intervention. Furthermore, parent levels of psychological flexibility increased during treatment, as well as through follow up. During follow up, parent protective responses and adolescent-reported levels of pain interference decreased significantly. The authors hypothesize that the delayed improvements observed in parental responses may indicate a potential mediating effect of psychological flexibility on parental responses.

A final study examined changes in pain-acceptance following CBT for chronic pain. While this study was not strictly an application of ACT, the treatment description suggests that there were some goals that were concordant. For example, the authors of the study noted that participants and their parents were told that the goal of treatment was not decrease pain, but to "increase coping skills, functioning, and quality of life" [34]. Thus, it seemed appropriate to include this study within the present review, particularly because it examined how changes in acceptance over the course of the treatment were related to changes in distress and disability. A total of 112 youth, aged 11-18, participated in the treatment program, which included daily relaxation training, physical therapy, occupational therapy, recreation therapy, family therapy, and psychotherapy groups. Levels of acceptance significantly increased during treatment, while levels of depression, pain catastrophizing, and functional disability significantly decreased. Importantly, changes in acceptance significantly predicted changes in all psychosocial variables and functional disability.

\section{Measures of ACT Processes in Youth with Chronic Pain and Their Families}

Table 1 describes self-report measures for youth and their caregivers that assess constructs relevant to ACT processes and their relation with other psychosocial measures of pain-related functioning. In brief, to date there are four measures that explicitly measure ACT processes in children and adolescents, and three questionnaires developed for use with caregivers either as a proxy report $(n=1)$ or a report of the caregiver's own experience and behaviors $(n=3)$. Three measures not specifically validated with pediatric chronic pain populations were included due to their utility in assessing ACT processes [57-59]. Further research and evaluation on all of the measures is warranted, as the statistical 
properties have only been preliminarily validated. Notably, however, findings from the published cross-sectional studies with pediatric samples are consistent with similar studies in adults and illustrate that ACT-relevant processes are related to functioning in a manner consistent with the underlying theory of ACT (e.g., greater pain acceptance is associated with better emotional and physical status).

Table 1. Measures of Acceptance and Commitment Therapy (ACT) processes in pediatric chronic pain.

\begin{tabular}{|c|c|c|}
\hline Measures & Description & Relations \\
\hline \multicolumn{3}{|l|}{ Child Specific } \\
\hline $\begin{array}{l}\text { Chronic Pain Acceptance } \\
\text { Questionnaire: Adolescent version } \\
\text { (CPAQ-A; }[60,61])\end{array}$ & $\begin{array}{l}20 \text { item self-report measure, } \\
\text { adapted from the adult version } \\
\text { [33]. Assesses two aspects of pain } \\
\text { acceptance: (1) Activity } \\
\text { Engagement and (2) Pain } \\
\text { Willingness. Response options } \\
\text { range from (0) never true to (4) } \\
\text { always true. }\end{array}$ & $\begin{array}{l}\text { Correlated with disability, depression, } \\
\text { anxiety, self-efficacy. Not correlated } \\
\text { with pain-specific variables } \\
\text { (e.g., pain duration). }\end{array}$ \\
\hline $\begin{array}{l}\text { Child and Adolescent Mindfulness } \\
\text { Measure (CAMM; [58])* }\end{array}$ & $\begin{array}{l}10 \text { item measure of mindfulness } \\
\text { skills. Normed on four samples of } \\
\text { school age children and } \\
\text { adolescents. Response options } \\
\text { range from (0) never true to (4) } \\
\text { always true. }\end{array}$ & $\begin{array}{l}\text { Correlated with quality of life, school } \\
\text { and social functioning and } \\
\text { mindfulness-inconsistent processes } \\
\text { (e.g., externalizing behavior). }\end{array}$ \\
\hline $\begin{array}{l}\text { Avoidance and Fusion } \\
\text { Questionnaire for Youth } \\
(\text { AFQ-Y; [57])* }\end{array}$ & $\begin{array}{l}17 \text { item measure of psychological } \\
\text { inflexibility for youth. There is } \\
\text { also a validated eight-item short } \\
\text { form of the AFQ-Y. }\end{array}$ & $\begin{array}{l}\text { Scores for both versions correlated } \\
\text { with child anxiety, somatic complaints, } \\
\text { mindfulness, quality of life, and } \\
\text { scholastic functioning. }\end{array}$ \\
\hline \multicolumn{3}{|l|}{ Parent specific } \\
\hline $\begin{array}{l}\text { Parent psychological flexibility } \\
\text { measure (PPFQ; }[43,62])\end{array}$ & $\begin{array}{l}24 \text { item measure to assess parental } \\
\text { levels of psychological flexibility } \\
\text { in responses to child's pain } \\
\text { symptoms. Items range from (0) } \\
\text { never true to (6) always true. }\end{array}$ & $\begin{array}{l}\text { Scores correlated with child disability, } \\
\text { depression, and pain acceptance, as } \\
\text { well as with parental response } \\
\text { behaviors, as assessed by the Adult } \\
\text { Responses to Child Symptoms (ARCS) } \\
\text { measure [63]. }\end{array}$ \\
\hline $\begin{array}{l}\text { Chronic Pain Acceptance } \\
\text { Questionnaire: Parent report } \\
\text { (CPAQ-P; [64]) }\end{array}$ & $\begin{array}{l}16 \text { item self-report measure of } \\
\text { parent perceptions of child's } \\
\text { acceptance of pain, adapted from } \\
\text { the adult CPAQ [33]. Same two } \\
\text { subscales as the CPAQ-A. } \\
\text { Response options range from (0) } \\
\text { never true to (6) always true. }\end{array}$ & $\begin{array}{l}\text { Scores correlated with child pain } \\
\text { intensity and disability, as well as } \\
\text { parent pain catastrophizing, } \\
\text { pain-related fear, and maladaptive } \\
\text { protective responses. }\end{array}$ \\
\hline $\begin{array}{l}\text { Parent Pain Acceptance } \\
\text { Questionnaire (PPAQ; [42]) }\end{array}$ & $\begin{array}{l}15 \text { item self-report measure of } \\
\text { parent's own levels of acceptance } \\
\text { towards their child's pain. } \\
\text { Adapted from the CPAQ-P [64]. } \\
\text { Two sub-scales: (1) Activity } \\
\text { Engagement and (2) Pain-related } \\
\text { Thoughts and Feelings. }\end{array}$ & $\begin{array}{l}\text { Scores correlated with child pain } \\
\text { acceptance, pain-related fear, and pain } \\
\text { catastrophizing, as well as parental } \\
\text { maladaptive responses to pain and } \\
\text { pain catastrophizing }\end{array}$ \\
\hline $\begin{array}{l}\text { Parental Acceptance and Action } \\
\text { Questionnaire (PAAQ [59]) * }\end{array}$ & $\begin{array}{l}15 \text { item self-report measure of } \\
\text { experiential avoidance in relation } \\
\text { to parenting. Two subscales: (1) } \\
\text { Inaction and (2) Unwillingness }\end{array}$ & $\begin{array}{l}\text { In preliminary validation, the PAAQ } \\
\text { correlated with symptoms of child } \\
\text { psychopathology and measures of } \\
\text { controlling parental behaviors and } \\
\text { affective expression. Predicted } \\
\text { significant amounts of variance in } \\
\text { parent and clinician ratings of child } \\
\text { anxiety symptoms. }\end{array}$ \\
\hline
\end{tabular}




\section{Strengths, Limitations, and Future Directions}

ACT takes a pragmatic and flexible approach to the treatment of pediatric pain. The overarching goal of ACT is to decrease ineffective struggles for control of pain or distressing emotions and increase adaptive responses to pain and facilitate consistent re-engagement with valued activities. Theoretically, the probability of this occurring is assumed to be more likely when one approaches aversive experiences with more openness and fewer struggles for control, and when one is more aware of both one's personal values and currently available opportunities to engage in valued activities.

Although preliminary, the growing body of evidence regarding ACT for pediatric pain is promising and results from existing studies are consistent, offering some support regarding validity and utility. Notably, and unfortunately, the number of studies on ACT for pediatric pain patients is considerably smaller than the body of research and strong evidence for using ACT for adult chronic pain [65]. Furthermore, beyond a small number of studies, the literature on ACT for children and adolescents suffers from either an absence of or poorly defined control conditions, and small sample sizes. Thus, there is a need for more studies and those of higher quality in terms of study design, evaluation across settings (e.g., outpatient, day hospital, individual vs. group), and further identification and replication of the mechanisms by which improvements in functioning occur during treatment. Formal inclusion of parents in treatment and assessment of parent pain-related functioning is also needed to illuminate and optimize their role in their child's pain rehabilitation.

At present, there is also a need for precise measurement of ACT treatment processes in youth with chronic pain. The adult chronic pain literature boasts numerous measures of ACT constructs, such as psychological flexibility [66,67], pain acceptance [33], engagement in valued activities [68-70], and committed action [38], which could potentially be adapted for use with pediatric populations. While there is one measure of pain acceptance for youth, it is curious that no measure of values or assessments related to other aspects of the model have been developed yet for pediatric chronic pain populations. Given the focus within ACT on improvements in values-based actions, the development of a robust measurement method in young people with chronic pain appears highly important. In particular, valued domains in adults may be different than in youth and these differences may require a carefully considered assessment. Furthermore, clinical experience suggests that certain times in one's life, for example, adolescence, are a time of personal determination of what is of personal value. For example, there can be consideration and weighing of socially-constructed values (e.g., be popular) in relation to those that are more personal in nature (e.g., be kind to others). The adult literature on values assessment offers little to no guidance on the assessment of "values formation" (for lack of a better term) and this seems a distinct and important opportunity for those that work in pediatric settings. In addition, further specification of the unique and interactive effects of caregiver and child responses to pain within an ACT framework appears to present an important opportunity for further work. Thus, while some aspects of the ACT model may be appropriate to assess via a process of "downward" extension from adults to youth, there may be particular facets of the pediatric setting that are deserving of careful consideration.

There are several additional considerations in relation to the use of ACT in the treatment of pediatric chronic pain. First, there is little guidance on ages that are appropriate or inappropriate for ACT; notably, only two of the ten studies reviewed explicitly made mention of developmental adaptations or considerations taken into their protocol [31,55]. In particular, it is not currently known if there is a minimum age, or minimum set of developmental milestones that must have been met, for successful treatment participation. The authors' clinical experience suggests somewhere in the 8-10 range may be a lower age limit, but this intuition is in need of empirical examination. Second, there is little guidance on the selection of type of psychological treatment, for example, use of ACT instead of CBT. Given the overlap between approaches, it may be that firm data-based rubrics are unlikely in the near future. Furthermore, given the distinctions between ACT and CBT, as detailed in the first major section of this paper, perhaps ACT is more relevant for use in individuals with significant deficits in values clarity and pursuit of values-based directions, or in those who are so paralyzed by 
pain and associated cognitions that cognitive methods are unlikely to work in an efficient manner. Third, while caregiver involvement in treatment is important and there is evidence demonstrating that caregiver responses and functioning impact child outcomes, the exact type or duration of such involvement is not clear. For example, is it sufficient to simply have caregivers sit in on some or all treatment sessions, or is it necessary for caregivers to receive treatment specific to their particular needs? Again, clinical experience suggests that the latter is more likely to be of use, but, to our knowledge, there are no data to use for guidance. It seems fair to note that these three issues are important for psychological interventions for pediatric chronic pain writ large and seem necessary to address for the field to move forward to firmer empirical ground.

\section{Conclusions}

To conclude, a primary goal of ACT for pediatric chronic pain is to support youth in healthy functioning and aid them in the process of re-engagement in valued activities so that their focus may shift back to age- appropriate activities, rather than predominantly on pain control or pain avoidance. The theoretical principles of ACT provide a framework for the structure of such treatment. While the extant data is promising, much more work needs to be done to augment the evidence base for the application of ACT with pediatric pain populations and to ensure that clinical practice is consistent with the hypothesized theoretical principles of ACT.

Acknowledgments: This work was supported by funding from the National Institutes of Health (R34AT008398; PI: Kevin E. Vowles) and the National School of Research in Health Care Science (PI: Rikard Wicksell).

Author Contributions: M.P. and K.E.V. conceived of the idea for this topical review and outlined the paper. M.P. performed the literature search, summarized findings for studies and measures, and put together an initial draft of the paper. K.E.V. wrote and finalized the introduction, provided edits and feedback. R.W. contributed to the conceptual organization of the paper, wrote up summaries on processes of change related studies, and provided valuable edits and feedback to finalize the paper.

Conflicts of Interest: The authors declare no conflict of interest.

\section{References}

1. King, S.; Chambers, C.T.; Huguet, A.; MacNevin, R.C.; McGrath, P.J.; Parker, L.; MacDonald, A.J. The epidemiology of chronic pain in children and adolescents revisited: A systematic review. Pain 2011, 152, 2729-2738. [CrossRef] [PubMed]

2. Huguet, A.; Miró, J. The severity of chronic pediatric pain: An epidemiological study. J. Pain 2008, 9, $226-236$. [CrossRef] [PubMed]

3. Noel, M.; Groenewald, C.B.; Beals-Erickson, S.E.; Gebert, J.T.; Palermo, T.M. Chronic pain in adolescence and internalizing mental health disorders: A nationally representative study. Pain 2016, 157, 1333-1338. [CrossRef] [PubMed]

4. $\quad$ Loeser, J.D.; Melzack, R.; Melzack, R.; Wall, P.; Levine, J.; Taiwo, Y.; Dubner, R.; Ruda, M.; Gracely, R.; Lynch, S.; et al. Pain: An overview. Lancet 1999, 353, 1607-1609. [CrossRef]

5. van Damme, S.; Crombez, G.; Eccleston, C. Coping with pain: A motivational perspective. Pain 2008, 139, 1-4. [CrossRef] [PubMed]

6. Woolf, C.J.; Bennett, G.J.; Doherty, M.; Dubner, R.; Kidd, B.; Koltzenburg, M.; Lipton, R.; Loeser, J.D.; Payne, R.; Torebjork, E. Towards a mechanism-based classification of pain? Pain 1998, 77, 227-229. [CrossRef]

7. Simons, L.E.; Kaczynski, K.J. The Fear Avoidance model of chronic pain: Examination for pediatric application. J. Pain 2012, 13, 827-835. [CrossRef] [PubMed]

8. Asmundson, G.J.G.; Noel, M.; Petter, M.; Parkerson, H.A. Pediatric fear-avoidance model of chronic pain: Foundation, application and future directions. Pain Res. Manag. 2012, 17, 397-405. [CrossRef] [PubMed]

9. Lethem, J.; Slade, P.D.; Troup, J.D.; Bentley, G. Outline of a Fear-Avoidance Model of exaggerated pain perception-I. Behav. Res. Ther. 1983, 21, 401-408. [CrossRef]

10. Vlaeyen, J.W.; Linton, S.J. Fear-avoidance and its consequences in chronic musculoskeletal pain: A state of the art. Pain 2000, 85, 317-332. [CrossRef] 
11. Leeuw, M.; Goossens, M.E.J.B.; Linton, S.J.; Crombez, G.; Boersma, K.; Vlaeyen, J.W.S. The fear-avoidance model of musculoskeletal pain: Current state of scientific evidence. J. Behav. Med. 2007, 30, 77-94. [CrossRef] [PubMed]

12. Guite, J.W.; McCue, R.L.; Sherker, J.L.; Sherry, D.D.; Rose, J.B. Relationships among pain, protective parental responses, and disability for adolescents with chronic musculoskeletal pain: The mediating role of pain catastrophizing. Clin. J. Pain 2011, 27, 775-781. [CrossRef] [PubMed]

13. Logan, D.E.; Simons, L.E.; Carpino, E.A. Too sick for school? Parent influences on school functioning among children with chronic pain. Pain 2012, 153, 437-443. [CrossRef] [PubMed]

14. Palermo, T.M.; Valrie, C.R.; Karlson, C.W. Family and parent influences on pediatric chronic pain: A developmental perspective. Am. Psychol. 2014, 69, 142-152. [CrossRef] [PubMed]

15. Chow, E.T.; Otis, J.D.; Simons, L.E. The longitudinal impact of parent distress and behavior on functional outcomes among youth with chronic pain. J. Pain 2016, 17, 729-738. [CrossRef] [PubMed]

16. Simons, L.E.; Smith, A.; Kaczynski, K.; Basch, M. Living in fear of your child's pain: The Parent Fear of Pain Questionnaire. Pain 2015, 156, 694-702. [CrossRef] [PubMed]

17. Hayes, S.C.; Strosahl, K.D.; Wilson, K.G. Acceptance and Commitment Therapy: The Process and Practice of Mindful Change, 2nd ed.; Guilford Press: New York, NY, USA, 2012.

18. Zettle, R.D. The Evolution of a Contextual Approach to Therapy: From Comprehensive Distancing to ACT. Int. J. Behav. Consult. Ther. 2005, 1, 77-89. [CrossRef]

19. Biglan, A.; Hayes, S.C. Should the behavioral sciences become more pragmatic? The case for functional contextualism in research on human behavior. Appl. Prev. Psychol. 1996, 5, 47-57. [CrossRef]

20. Noel, M.; Petter, M.; Parker, J.A.; Chambers, C.T. Cognitive Behavioral Therapy for Pediatric Chronic Pain: The Problem, Research, and Practice. J. Cogn. Psychother. 2012, 26, 143-156. [CrossRef]

21. Palermo, T.M.; Law, E.F.; Bromberg, M.; Fales, J.; Eccleston, C.; Wilson, A.C. Problem Solving Skills Training for Parents of Children with Chronic Pain: A Pilot Randomized Controlled Trial. Pain 2016, 157, 1213-1223. [CrossRef] [PubMed]

22. Hayes, S.C.; Bissett, R.; Korn, Z.; Zettle, R.D.; Rosenfarb, I.; Cooper, L.; Grundt, A. The impact of acceptance versus control rationales on pain tolerance. Psychol. Rec. 1999, 49, 33-47.

23. Keogh, E.; Bond, F.W.; Hanmer, R.; Tilston, J. Comparing acceptance- and control-based coping instructions on the cold-pressor pain experiences of healthy men and women. Eur. J. Pain 2005, 9, 591-598. [CrossRef] [PubMed]

24. McMullen, J.; Barnes-Holmes, D.; Barnes-Holmes, Y.; Stewart, I.; Luciano, C.; Cochrane, A. Acceptance versus distraction: Brief instructions, metaphors and exercises in increasing tolerance for self-delivered electric shocks. Behav. Res. Ther. 2008, 46, 122-129. [CrossRef] [PubMed]

25. Gutiérrez, O.; Luciano, C.; Rodríguez, M.; Fink, B.C. Comparison between an acceptance-based and a cognitive-control-based protocol for coping with pain. Behav. Ther. 2004, 35, 767-783. [CrossRef]

26. Masedo, A.I.; Esteve, M.R. Effects of suppression, acceptance and spontaneous coping on pain tolerance, pain intensity and distress. Behav. Res. Ther. 2007, 45, 199-209. [CrossRef] [PubMed]

27. Branstetter-Rost, A.; Cushing, C.; Douleh, T. Personal values and pain tolerance: Does a values intervention add to acceptance? J. Pain 2009, 10, 887-892. [CrossRef] [PubMed]

28. Vowles, K.E.; McNeil, D.W.; Gross, R.T.; McDaniel, M.L.; Mouse, A.; Bates, M.; Gallimore, P.; McCall, C. Effects of pain acceptance and pain control strategies on physical impairment in individuals with chronic low back pain. Behav. Ther. 2007, 38, 412-425. [CrossRef] [PubMed]

29. Páez-Blarrina, M.; Luciano, C.; Gutiérrez-Martínez, O.; Valdivia, S.; Ortega, J.; Rodríguez-Valverde, M. The role of values with personal examples in altering the functions of pain: Comparison between acceptance-based and cognitive-control-based protocols. Behav. Res. Ther. 2008, 46, 84-97. [CrossRef] [PubMed]

30. McCracken, L.M.; Vowles, K.E. Acceptance and Commitment Therapy and mindfulness for chronic pain: Model, process, and progress. Am. Psychol. 2014, 69, 178-187. [CrossRef] [PubMed]

31. Wicksell, R.K.; Dahl, J.; Magnusson, B.; Olsson, G.L. Using acceptance and commitment therapy in the rehabilitation of an adolescent female with chronic pain: A case example. Cogn. Behav. Pract. 2005, 12, 415-423. [CrossRef]

32. Vowles, K.E.; Sowden, G.; Ashworth, J. A comprehensive examination of the model underlying acceptance and commitment therapy for chronic pain. Behav. Ther. 2014, 45, 390-401. [CrossRef] [PubMed] 
33. LMcCracken, M.; Vowles, K.E.; Eccleston, C. Acceptance of chronic pain: Component analysis and a revised assessment method. Pain 2004, 107, 159-166. [CrossRef]

34. Weiss, K.E.; Hahn, A.; Wallace, D.P.; Biggs, B.; Bruce, B.K.; Harrison, T.E. Acceptance of pain: Associations with depression, catastrophizing, and functional disability among children and adolescents in an interdisciplinary chronic pain rehabilitation program. J. Pediatr. Psychol. 2013, 38, 756-765. [CrossRef] [PubMed]

35. Kalapurakkel, S.; Carpino, E.A.; Lebel, A.; Simons, L.E. 'pain can't stop Me': Examining pain self-efficacy and acceptance as resilience processes among youth with chronic headache. J. Pediatr. Psychol. 2014, 40, 926-933. [CrossRef] [PubMed]

36. Hayes, S.C.; Shenk, C. Operationalizing Mindfulness Without Unnecessary Attachments. Clin. Psychol. Sci. Pract. 2006, 11, 249-254. [CrossRef]

37. McCracken, L.M.; Gauntlett-Gilbert, J.; Vowles, K.E. The role of mindfulness in a contextual cognitive-behavioral analysis of chronic pain-related suffering and disability. Pain 2007, 131, 63-69. [CrossRef] [PubMed]

38. McCracken, L.M. Committed action: An application of the psychological flexibility model to activity patterns in chronic pain. J. Pain 2013, 14, 828-835. [CrossRef] [PubMed]

39. Vowles, K.; Fink, B.; Cohen, L. Acceptance and Commitment Therapy for chronic pain: A diary study of treatment process in relation to reliable change in disability. J. Context. Behav. Sci. 2014, 3, 74-80. [CrossRef] [PubMed]

40. Vowles, K.E.; Thompson, M. Acceptance and Commitment Therapy for chronic pain. In Mindfulness and Acceptance in Behavioral Medicine: Current Theory and Practice; McCracken, L.M., Ed.; New Harbinger Publications: Oakland, CA, USA, 2011; pp. 31-60.

41. Wicksell, R.K.; Olsson, G.L.; Hayes, S.C. Mediators of change in acceptance and commitment therapy for pediatric chronic pain. Pain 2011, 152, 2792-2801. [CrossRef] [PubMed]

42. Smith, A.M.; Sieberg, C.B.; Odell, S.; Randall, E.; Simons, L.E. Living Life With My Child's Pain. Clin. J. Pain 2015, 31, 633-641. [CrossRef] [PubMed]

43. Wallace, D.P.; McCracken, L.M.; Weiss, K.E.; Harbeck-Weber, C. The role of parent psychological flexibility in relation to adolescent chronic pain: Further instrument development. J. Pain 2015, 16, 235-246. [CrossRef] [PubMed]

44. Wicksell, R.K.; Melin, L.; Lekander, M.; Olsson, G.L. Evaluating the effectiveness of exposure and acceptance strategies to improve functioning and quality of life in longstanding pediatric pain-A randomized controlled trial. Pain 2009, 141, 248-257. [CrossRef] [PubMed]

45. Casier, A.; Goubert, L.; Theunis, M.; Huse, D.; de Baets, F.; Matthys, D.; Crombez, G. Acceptance and well-being in adolescents and young adults with cystic fibrosis: A prospective study. J. Pediatr. Psychol. 2011, 36, 476-487. [CrossRef] [PubMed]

46. Arch, J.J.; Craske, M.C. Acceptance and Committment Therapy and Cognitive Behavioral Therapy for anxiety disorders: Different treatments, similar mechanisms? Clin. Psychol. Sci. Pract. 2008, 15, 263-279. [CrossRef]

47. Kallesøe, K.H.; Schröder, A.; Wicksell, R.K.; Fink, P.; Ørnbøl, E.; Rask, C.U. Comparing group-based acceptance and commitment therapy (ACT) with enhanced usual care for adolescents with functional somatic syndromes: A study protocol for a randomised trial. BMJ Open 2016, 6, e012743. [CrossRef] [PubMed]

48. Wicksell, R.K.; Kanstrup, M.; Kemani, M.K.; Holmström, L.; Olsson, G.L. Acceptance and Commitment Therapy for children and adolescents with physical health concerns. Curr. Opin. Psychol. 2015, 2, 1-5. [CrossRef]

49. Halliburton, A.E.; Cooper, L.D. Applications and adaptations of Acceptance and Commitment Therapy (ACT) for adolescents. J. Context. Behav. Sci. 2014, 4, 1-11. [CrossRef]

50. Murrell, A.R.; Coyne, L.W.; Wilson, K.G. ACT with children, adolescents, and their parents. In A Practical Guide to Acceptance and Commitment Therapy; Hayes, S.C., Strosahl, K.D., Eds.; Springer: New York, NY, USA, 2005.

51. Palermo, T.M.; Chambers, C.T. Parent and family factors in pediatric chronic pain and disability: An integrative approach. Pain 2005, 119, 1-4. [CrossRef] [PubMed]

52. Wicksell, R.K.; Melin, L.; Olsson, G.L. Exposure and acceptance in the rehabilitation of adolescents with idiopathic chronic pain-A pilot study. Eur. J. Pain 2007, 11, 267-274. [CrossRef] [PubMed] 
53. Ghomian, S.; Shairi, M.R. The Effectiveness of Acceptance and Commitment Therapy for Children with Chronic Pain on the Quality of Life on 7 to 12. Int. J. Pediatr. 2014, 2, 47-56.

54. Gauntlett-Gilbert, J.; Connell, H.; Clinch, J.; Mccracken, L.M. Acceptance and values-based treatment of adolescents with chronic pain: Outcomes and their relationship to acceptance. J. Pediatr. Psychol. 2013, 38, 72-81. [CrossRef] [PubMed]

55. Martin, S.; Wolters, P.L.; Toledo-Tamula, M.A.; Schmitt, S.N.; Baldwin, A.; Starosta, A.; Gillespie, A.; Widemann, B. Acceptance and commitment therapy in youth with neurofibromatosis type 1 (NF1) and chronic pain and their parents: A pilot study of feasibility and preliminary efficacy. Am. J. Med. Genet. Part A 2016, 170, 1462-1470. [CrossRef] [PubMed]

56. Wallace, D.P.; Woodford, B.; Connelly, M. Promoting psychological flexibility in parents of adolescents with chronic pain: Pilot study of an 8-week group intervention. Clin. Pract. Pediatr. Psychol. 2016, 4, 405-416. [CrossRef]

57. Greco, L.A.; Lambert, W.; Baer, R.A. Psychological inflexibility in childhood and adolescence: Development and evaluation of the Avoidance and Fusion Questionnaire for Youth. Psychol. Assess. 2008, 20, 93-102. [CrossRef] [PubMed]

58. Greco, L.A.; Baer, R.A.; Smith, G.T. Assessing mindfulness in children and adolescents: Development and validation of the Child and Adolescent Mindfulness Measure (CAMM). Psychol. Assess. 2011, 23, 606-614. [CrossRef] [PubMed]

59. Cheron, D.M.; Ehrenreich, J.T.; Pincus, D.B. Assessment of parental experiential avoidance in a clinical sample of children with anxiety disorders. Child Psychiatry Hum. Dev. 2009, 40, 383-403. [CrossRef] [PubMed]

60. McCracken, L.M.; Gauntlett-Gilbert, J.; Eccleston, C. Acceptance of pain in adolescents with chronic pain: Validation of an adapted assessment instrument and preliminary correlation analyses. Eur. J. Pain 2010, 14, 316-320. [CrossRef] [PubMed]

61. Wallace, D.P.; Harbeck-Weber, C.; Whiteside, S.P.H.; Harrison, T.E. Adolescent acceptance of pain: Confirmatory factor analysis and further validation of the chronic pain acceptance Questionnaire, Adolescent version. J. Pain 2011, 12, 591-599. [CrossRef] [PubMed]

62. McCracken, L.M.; Gauntlett-Gilbert, J. Role of psychological flexibility in parents of adolescents with chronic pain: Development of a measure and preliminary correlation analyses. Pain 2011, 152, 780-785. [CrossRef] [PubMed]

63. Walker, L.S.; Levy, R.L.; Whitehead, W.E. Validation of a measure of protective parent responses to children's pain. Clin. J. Pain 2006, 22, 712-716. [CrossRef] [PubMed]

64. Simons, L.E.; Sieberg, C.B.; Kaczynski, K.J. Measuring parent beliefs about child acceptance of pain: A preliminary validation of the Chronic Pain Acceptance Questionnaire, parent report. Pain 2011, 152, 2294-2300. [CrossRef] [PubMed]

65. Society of Clinical Psychology. Acceptance and Committment Therapy for Chronic Pain; American Psychological Association: Washington, DC, USA, 2013; Available online: http://www.div12.org/ PsychologicalTreatments/treatments/chronicpain_act.html (accessed on 21 May 2015).

66. Vowles, K.; McCracken, L.; Sowden, G.; Ashworth, J. Psychological flexibility in coping with chronic pain: Further examination of the brief pain coping inventory-2. Clin. J. Pain 2014, 30, 324-330. [CrossRef] [PubMed]

67. McCracken, L.M.; Vowles, K.E. Psychological flexibility and traditional pain management strategies in relation to patient functioning with chronic pain: An examination of a revised instrument. J. Pain 2007, 8, 700-707. [CrossRef] [PubMed]

68. McCracken, L.M.; Yang, S. The role of values in a contextual cognitive-behavioral approach to chronic pain. Pain 2006, 123, 137-145. [CrossRef] [PubMed]

69. Jensen, M.P.; Vowles, K.E.; Johnson, L.E.; Gertz, K.J. Living well with pain: Development and preliminary evaluation of the Valued Living Scale. Pain Med. 2015, 16, 2109-2120. [CrossRef] [PubMed]

70. Pielech, M.; Bailey, R.W.; McEntee, M.L.; Ashworth, J.; Levell, J.; Sowden, G.; Vowles, K.E. Preliminary evaluation of the values tracker: A two-item measure of engagement in valued activities in those with chronic pain. Behav. Modif. 2016, 40, 239-256. [CrossRef] [PubMed]

(C) 2017 by the authors; licensee MDPI, Basel, Switzerland. This article is an open access article distributed under the terms and conditions of the Creative Commons Attribution (CC BY) license (http:/ / creativecommons.org/licenses/by/4.0/). 